\title{
Accounting In The Social Menu
}

José Villacís González, Universidad CEU San Pablo, Spain

\begin{abstract}
This paper was born out of combinatorics. It defines a level of utility which, though it cannot be measured, can be preferred to another in each specific combination of goods. In turn, each combination defines a menu, meaning that there will be as many menus as there are combinations of goods. In this manner, we have a menu and a utility for each combination of goods. Armed with these mathematical knowns, we can then proceed to carry out two kinds of accounting acts or reckonings, from lowest to highest; i.e. the accounting entry for the menus for each individual and the accounting entry for the social menus.
\end{abstract}

Keywords: combinatory, menu, accounting, permutations

\section{INTRODUCTION}

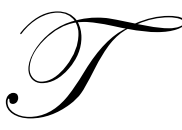

his article draws on other essays on individual menus, on collective negotiating and on the theories of bribes. There will be a number of introductory sections that are common to these subjects and which will be necessary in order to achieve the desired goal: social accounting.

The purpose of this paper is to account for, using accounting techniques, the potential and real menus a person has to satisfy his or her wishes in a reasonable hedonistic way. In order to know the number of menus needed, we have to count them and to do this, we have to know something else - all possible combinations in the order of consumption.

While it is true that each good generates a level of utility, two or more goods generate a level of utility in their ordinal temporal consumption. The important thing about this paper and about the theory of consumption is to know that each combination or, rather, the manner of combining determines a specific level of utility.

Once we know the menus for each individual, we can calculate the menus of the social group.

\section{LOTS AND MENUS}

We use the expression 'a lot of goods' to denote the goods, their nature and number provided to each individual for consumption. This 'lot of goods' may be combined or ordered in various ways in the manner that best suits each individual in optimising the utility obtained.

Really and, above all, mathematically, it is possible to rank each good differently for the purpose, as noted, of optimising their utility. But in order to optimise their utility, it is necessary to know all possible combinations and only then choose.

We use the term 'menu' to denote each combination or ranking of the goods that the lot of goods is known to contain. Consequently, there will be as many menus as there are combinations. The consumers must know all possible menus; i.e. all possible combinations, in order to be able to choose the combination that best suits them and thereby optimise their utility.

We then measure all the menus and assign to each menu a certain level of utility. 


\section{ORDINALITY}

As explained in the foregoing section we start off with a lot, i.e. an undifferentiated collection of identifiable goods. With these goods we can then carry out various possible combinations, each combination constituting a given menu.

However, a complication arises when we come to measuring utility. We can get round this if we put measuring utility to one side and apply a criterion of preference, i.e., if we establish criteria of selection for each menu.

The thinking behind this is as follows: once we have carried out and noted the combinations, we will then know and can count the menus. That is the first step. The next step consists of establishing a link or chain of preference for each group of combined goods.

If for each group of three combinations (we do not say three goods but three groups of goods), designated $\mathrm{A}, \mathrm{B}, \mathrm{C}$, the preferences $(\mathrm{P})$ will be: A is preferred to B; B is preferred to C; and therefore APC.

\section{APB, BPC, APC}

In reality with three groups of goods there are two preferences, given that the last, APC (A is preferred to C) is a purely temporary consequence of the two previous preferences.

In short, once we know the menus and the different levels of their respective utilities, we can establish a chain but one of preferences. In the example, three groups less one group, equal two groups.

\section{THE SCALE}

If each individual comprehends and defines a series of menus, all possible menus, and if each menu determines a utility, we can count those levels of utility and, thus, construct that person's chain of preferences.

Thus, if there is a chain of preferences or menus, each menu will define a level on a scale. This scale of preferences allows us to see to what extent each scale is preferred and in what order it stands with respect to all other levels. Thus, given certain combinations, each individual relates each scale to all the rest, given that all the menus, all combinations of goods, are ordered according to a scale of preferences. The scale will have $\mathrm{m}$ ! levels and be a relation of preferences and comparisons.

\section{ACCOUNTING AND COMBINATORIC THEORY}

From here we proceed to accounting for the menus of each individual and, then, of all individuals. Before dealing with the entire range we need to take on board a series of assumptions in order to permit an overall count.

\section{Assumptions}

We assume that all individuals have the same initial lot of goods, which we denote as $\mathbf{~ m . ~}$

We assume that there are $\mathbf{n}$ individuals.

We assume that there no two combinations that generate the same level of utility. Supposing this leads the conclusion explained below, that each individual will have as many menus and levels of utility as there are combinations. 


\section{Accounting for Each Individual}

In general terms combinatorics is the area of mathematics that focuses on different ways of grouping elements. Within combinatorics there is a field which accounts for each specific case in which all rankings of all goods are involved without there being a single repetition.

This area of combinatorics is known as 'ordinary permutations'.

We are interested in discovering the number of ordinary permutations because this will allows us to know all the menus available to a single individual.

There being $\mathbf{m}$ goods, the formula for obtaining the ordinary permutations to thereby discover all possible combinations, is as follows:

$\mathrm{m} !$

In the case of seven goods, the total possible menus will be: $7 !=7.6 .5 .4 .3 .2 .1=5,040$.

This means that from five goods we can create 5,040 different menus, each of which, as stated above, will generate a different level of utility (which it does not concern us to measure).

\section{Social Accounting}

We next attempt to answer the question: how many social menus will there be in a group of $\mathrm{n}$ individuals. This question presupposes that we have already answered a prior question: what is a menu? Something that exists $a$ priori in the subjective field of vision of the individual or something that has been consumed? We will see why this is relevant in the following example.

Suppose there are two goods: a and $\mathrm{b}$. One combination could be $(\mathrm{a}, \mathrm{b})$, which we will call $\mathrm{A}$, and the other $(b, a)$, which we will call B. Let there be two individuals: individual 1 and individual 2. Let us imagine that they both choose the first group (a,b, or A) first, and next ( $\mathrm{b}, \mathrm{a})$, which is B. This tells us that a priori there are only two menus. This case will be defined by the fact that the menus will be consumed in that order. The menus can be noted in the following way: APB. This is a manner of counting and choosing two groups.

These combinations or menus can be counted using the formula: $2 !=2.1=2$

If we are looking for the menus consumed, we can say that there are two, the possible combinations: $2 !=2$, multiplied by the two individuals, individual 1 and individual 2. Each individual will say that he or she has consumed each menu, i.e. two menus, in which case the social menu will be reckoned as two times each menu. This statement is also true, provided that the individuals do not coincide with the same scales or preferences. In other words, it will be true provided that each individual maintains different scales with the same levels, in other words preference for different menus.

As there are two combinations and two individuals, the formula will be:

$\mathbf{m} ! . \mathbf{n}$

\section{WHOLE NUMBERS}

Menus are whole numbers to the extent that the combinations are whole numbers.

Both in individual accounting and social accounting of menus we state that numbers will be whole and not fractions. This affirmation is sustained on two grounds: 
1. On the counting. If, for example there are five goods, we can say that one or two goods are divided into $\mathbf{x}$ parts such that they alter the number of combinations.

2. On the preferences. If one combination of goods is preferred to another, the preferences will not have a value and thus no value can be divided between the two. This statement arises from the absence of measurement of the intensity of preference between two combinations. We cannot say that Group A is $\mathbf{x}$ times preferred to $\mathrm{B}$ and $\mathrm{B}$ is preferred, for example, $\mathbf{1} / \mathbf{x}$ times to $\mathrm{C}$.

Expressed graphically this means that the distances between the grades ( $\mathbf{m}$ grades) in each of $\mathbf{n}$ scales is identical. In other words there are no fractions or multiples of distance between grades. Any analyst, any individual, can move up or down the scale with their eyes shut at no risk of making a mistake and falling.

\section{HORIZONTAL SCALES IN THE SOCIAL GROUP}

The scale of one individual will not necessarily be the same as the scale of another individual, given that not only are the menus whole numbers, they also manifest preferences and the preferences of each consumer do not have to coincide. It may happen that some scales are similar or it may not.

In the case of $\mathbf{n}$ individuals having the same kind of combinations and preferences, once consumed, there will be $\mathrm{m}$ ! $\mathrm{n}$ scales. This means that they can be drawn and defined horizontally. Suppose there are 30 goods, of which 15 individuals prefer good A to good B. This does not mean that good A is preferred 15 times more than good B.

Given that cardinal numbers cannot be multiplied, this result is not possible, nor is it possible to build a vertical scale of multiples to which to add utilities. It may be that such a vertical scale could be defined with respect to public goods, but that is not the subject of this enquiry.

The key to the problem is that the ordinal or preference criteria that define the scale cannot be combined with the cardinal numbers resulting from counting the combinations of goods. The criteria of order/preference that we apply differ from the ordinal multiplier used in the treatment of scales.

\section{NUMBER OF PREFERENCES}

Let us therefore separate the idea of preferences, which are not quantitative but ordinal, from another, which is that of counting the number of preferences in the chain of preferences. In other words, instead of measuring the distance between one scale and another, or the intensity of the preference, we measure the ranking of each with respect to the rest. Applying this logic it then becomes possible to count the relation between scales. In other words we can count the scale stations in the chain of preferences. We have already seen this in the three groups of goods A, $\mathrm{B}$ and $\mathrm{C}$. The chain of preferences was two. This, then, it is possible to count both with respect to an individual and with respect to a group of $\mathbf{n}$ individuals.

1. In the case of an individual whose lot is m goods and whose menus are $\mathbf{m}$ !, the chain of preferences will be:

m! -1

2. In the case of $\mathbf{n}$ individuals who consumed, the chain of preferences will be:

$(\mathbf{m} !-1) n$

This will be so, of course, provided that the utility of an individual obtained from a specific combination is not the same as that of another individual.

We stress that in accounting for the social menu, $\mathbf{m}$ menus chosen by $\mathbf{n}$ individuals can be interpreted in two ways: first in the sense that if it is the same menu chosen by $n$ individuals, it will be $\mathbf{m} ! \mathbf{n}$ menus, i.e. the same 
menu counted by $\mathbf{n}$ individuals. It could also be considered as one menu considered by $\mathbf{n}$ individuals ...

\section{APPLICATION}

This inquiry into the number of individual and social menus is also interesting for the public-sector economy, particularly in the area relating to negotiations among social groups.

The theory of strong groups bribing weak groups in order for decisions to be taken is theoretically viable using combinatorics.

Another area where work could be done is in applying combinatorics in cases of public goods auctioned among all social groups with no possibility of people declining to bid.

\section{CONCLUSION}

The combinatory mathematics, or combinatorics, that establish the number of times a series of goods forming part of a menu can be ranked, placed or preferred is useful for establishing a scale of utilities which, although it cannot be measured, can be ranked. If each menu determines a level of utility, it is possible to establish a chain of ordinal preferences which we call a scale.

On a scale, each grade is determined as being its utility with respect to others in a series of preferences. The menus or combinations $\mathbf{m}$ ! can be counted both in the case of one individual and in the case of $\mathbf{n}$ individuals. Once the individual menus have been set up as social menus, a chain of grades can be counted, the number of which will differ by a single unit from that of the chain of preferences.

Lastly, it is possible to count the individual menus and the social menus and thus the number of grades in the chain of preferences.

\section{AUTHOR INFORMATION}

Jose Villacis Gonzalez is a $\mathrm{PhD}$ in economic science; degree in political science and sociology; lecturer in economy at the University San Pablo-CEU; author of various books: Macroeconomía, Microeconomía, Política Monetaria y Política Fiscal; El Origen de la Macroeconomía en España; La Teoría de las Disponibilidades, del Interés y de la Renta; La Máquina de la superación de Leviathan; Germán Bernacer y el Círculo de Alicante.

\section{REFERENCES}

1. Auriol E. and Michel Benaim (2000), "Standardization in Decentralized Economics”, American Economic Review, pp550-570.

2. $\quad$ Arrow, J.K. (1963), "Social Choice and Individual Values", 2nd edit., 1951, New York, Wiley.

3. (1951), "Alternative Approaches to the Theory on Choice in Risk-Taking Situations", in Econometrica, 19, pp 404-37.

4. $\quad$ Arrow,K.F.-Debreu Gérard (1954), "Existence of an Equilibrium for a Competitive Economy”, in Econometrica, 265-90.

5. $\quad$ Arrow, J.K.,-Han, F.H.(1971), “General Competitive Analysis”, Edimburgh, Oliver\&Boyd.

6. Arrow, J.K.-Hurwicz, L.(1972), “An Optimality Criterion for Decision-Making Under Ignorance”, in C.F. Carter, J.L.(comps.), Uncertainty and Expectation in Economics, Oxford, Basil Blackwell.

7. $\quad$ Baumol, W. J.(1967), "Business Behaviour, Value and Growth", 2nd Edt., New York. 1959.

8. Becker, G. A.(1965), "A Theory of the Allocation of Time", Economic Journal, 75, pp 493-517.

9. Black, D. (1948), "On the Rationale of Group Decision-Making” Journal Publication Economics, pp 2324.

10. Black, J.(1962), “The Technical Progress Function and the Production Function”, in Econometrica, 29, pp 166-167.

11. Clark, J.B.(1893), “The Genesis of Capital”, Yale Review 2, pp 302-315. 
12. Clark, J.M.(1961), “Competition as a Dynamic Process”, Washington, Brooking.

13. Debreu, G. (1951), "The Coefficient of Resource Allocation”, Econometrica, pp 273-92.

14. Evans C. and Harrigan J (2005), "Distance, Time, and Specialization: Lean Retailing in General Equilibrium., American Economic Review, pp 292-313

15. Ford, J.L. (1983), “Choice, Expectation and Uncertainly”, Oxford, Basil, Blackwell .

16. Glazer, J. and Rubinstein A.(2004), “On Optimal Rules of Persuasion”, Econometrica, pp. 1715-1736.

17. Gnedenko, Boris and Khinchin Alexander.(1945), "An Elementary Introduction to the Theory of Probability". New York: Dover.

18. Hicks, John R. (1936), "Value and Capital” Oxford: Oxford University Press, (1945),

$19 . \quad$ (1965), “Capital and Growth”, Oxford, Oxford University Press.

20. Jevons, W. S. (1871), "Brief Account of a General Mathematical Theory of Political Economy” B.A,4 ${ }^{\text {th }}$ edit. Jevon.

21. Koopmans, T.C. (1957), "Three Essays on the State of Economic Science" New York.

22. Leontief, W.A. (1966), "Introduction to a Theory of the Internal Structure of Funtional Relationship", Econometrica, 15, in Leontieff

23. (1976), "Essays in Economics",Vol.2, Oxford, Basil Blackwell.

24. Machlup, F.(1955), "The Problem of Verification in Economics”, Southern Economic Journal, 22 , pp 1-21.

25. Marshall, A. (1 ${ }^{\mathrm{a} e d i c .1890), " P r i n c i p l e s ~ o f ~ E c o n o m i c s ”, ~} 8^{\mathrm{a}}$ edit.; edit. C.W. Guillevaud, Londres, McMillan, 1961.

26. Meade, J.E. (1955), “Trade and Welfare. The Theory of International Economic Policy”, vol.I, London.

27. Samuelson, Paul A.(1947) “Foundation of Economic Analysis”. Cambridge: Harvard University Press.

28. Tukey, John W. (1962), “Statistical and Quantitative Methodology.” Trends in Social Science (D P Ray, edt.). New York: Philosophical Library.

29. Villacís, José (1994) “Combinatorial Theory Applied to the Study of Production.” Esic Market 79, pp. 4357.

30. (2003), "Preferencias y Orden Combinatorio en Economía", Anales de la Real Academia de Doctores de España. Volumen 7, pp 191-208.

31. (2004)," Caos y Orden Combinatorio en Economía" Anuario Jurídico y Económico Escurialense. Época II, Número XXXVII-2004-ISSN: 1133-3677, 2003, pp. 143-168.

32. (2004)"Entropía, Caos y Teoría Combinatoria en La Economía" Anales de la Real Academia de Doctores de España" Volumen 8, pp. 143-168.

33. (2005), "Business Combinatorial Theory and Decision Making", The Journal of American Academy of Business, Cambridge, Vol.VI, n.1, March, pp.117-122.

34. Walras, Leon. (1874). “Elements of Pure Economics".Translation by William Jaffé. London: Allen \& Unwin, 1954. 